\title{
Review Article \\ Pharmacological Prevention of Posttraumatic Stress Disorder: A Systematic Review
}

\author{
Ravi Philip Rajkumar ${ }^{1}$ and Balaji Bharadwaj ${ }^{2}$ \\ ${ }^{1}$ Department of Psychiatry, Disaster Management Committee, Jawaharlal Institute of \\ Postgraduate Medical Education and Research (JIPMER), Puducherry 605 006, India \\ ${ }^{2}$ Department of Psychiatry, Jawaharlal Institute of Postgraduate Medical Education and Research (JIPMER), \\ Puducherry 605 006, India
}

Correspondence should be addressed to Ravi Philip Rajkumar; ravi.psych@gmail.com

Received 26 July 2014; Accepted 26 September 2014; Published 12 October 2014

Academic Editor: Takahiro Nemoto

Copyright (C) 2014 R. P. Rajkumar and B. Bharadwaj. This is an open access article distributed under the Creative Commons Attribution License, which permits unrestricted use, distribution, and reproduction in any medium, provided the original work is properly cited.

\begin{abstract}
Introduction. Various interventions, both psychological and pharmacological, have been studied for their efficacy in preventing posttraumatic stress disorder (PTSD) following trauma exposure. However, the preventive effect of pharmacotherapy has not been systematically assessed. Methodology. A systematic review of all clinical trials of drug therapy to prevent PTSD, available through the PubMed and EMBASE databases, was conducted. This included an assessment of each study's quality. Results. A total of 13 studies were reviewed. The drugs examined in these papers included propranolol, hydrocortisone, serotonin reuptake inhibitors, gabapentin, omega-3 fatty acids, and benzodiazepines. There was marked heterogeneity across studies in terms of quality, study populations, and methodology. Analysis of the outcomes revealed preliminary evidence for the efficacy of hydrocortisone, particularly in critical care settings. There was no consistent evidence to support the use of other drugs to prevent PTSD. Discussion. There may be a limited role for hydrocortisone in preventing the development of PTSD in specific settings. Results with other drugs are inconsistent. Further large-scale studies should assess the efficacy of these approaches in other contexts, such as natural disasters, and the time frame within which they should be used.
\end{abstract}

\section{Introduction}

Posttraumatic stress disorder (PTSD) is a common psychological consequence of exposure to trauma, particularly situations that threaten the safety or integrity of the self or loved ones. A wide range of traumatic situations has been associated with PTSD: combat situations, natural and man-made disasters, accidental injury, physical or sexual assault, and serious medical illnesses and their treatment [13]. PTSD consists of three distinctive groups of symptoms: reexperiencing the traumatic event, avoidance of reminders of the event, and hyperarousal. These symptoms should be present for at least one month and should cause significant impairment in social and occupational functioning $[1,4,5]$. Estimates of prevalence of PTSD in the general population have varied depending on study methodology, but rates as high as $12.3 \%$ have been reported, with prevalence in women generally higher than in men $[1,6]$. Following exposure to a natural or man-made disaster, prevalences as high as $40 \%$ have been reported [2].

The course of PTSD is variable, with some studies finding a favourable outcome and low rates of chronicity [7]; however, long-term studies have found that at least half the patients initially diagnosed with PTSD continue to experience symptoms after several years $[6,8,9]$. Chronic PTSD is associated with marked impairments in social and occupational functioning and is often associated with other mental disorders such as depression, anxiety disorders, and substance use disorders [10]. A variety of factors have been associated with the development or persistence of PTSD following a traumatic exposure: these include female gender, preexisting psychopathology, and the nature and severity of the exposure $[10,11]$.

One potential predictor of future PTSD is the appearance of initial PTSD-like symptoms following exposure to trauma. 
These symptoms, sometimes referred to as acute stress disorder (ASD) [12], do not qualify for a diagnosis of PTSD unless they persist for over a month. Not all individuals who experience ASD are diagnosed with PTSD in the long term $[13,14]$, but severe ASD, particularly associated with high levels of hyperarousal, is associated with the subsequent emergence of PTSD $[15,16]$.

With this in mind, a variety of psychological interventions have been designed both to address these acute symptoms and to prevent the future development of PTSD $[17,18]$; however, the efficacy of these interventions has been questioned $[19,20]$ and they may not be easily available in certain settings [21]. Recognition of these facts, as well as advances in understanding the biology of PTSD, has led to trials of various pharmacological agents immediately following a traumatic exposure to reduce the occurrence or severity of subsequent PTSD [22]. In this article, these approaches and the evidence for their efficacy are reviewed.

\section{Methodology}

2.1. Search Strategy. A search of the PubMed and EMBASE databases was carried out using the key words "posttraumatic stress disorder," "PTSD," "acute stress disorder," "pharmacotherapy," "drug therapy," and "prevention," including the PudMed medical subheadings "Stress Disorder, Posttraumatic/Drug Therapy" and "Stress Disorder, Posttraumatic/Prevention and Control." The references of these articles were checked for further papers of interest. Studies were included if they prospectively examined the effect of a pharmacological intervention on reducing the diagnosis or symptoms of PTSD at follow-up.

2.2. Outcomes. The primary outcome of interest was the diagnosis of PTSD as per standard criteria in patients receiving the intervention, as compared to those in the control group. Where this was not examined, secondary outcome measures, such as PTSD symptoms measured using a standardized rating scale, were assessed.

2.3. Data Extraction and Quality Assessment. All study data was extracted by the author and entered in the following format: study design, study duration, sample size, drug used with dose and duration, length of follow-up, outcome measures used, and results. The Jadad scoring system [23] was used to assess the methodological quality of these studies. This system assigns a score from 0 to 5 to a study, with higher scores indicating higher study quality, based on three items: randomization ( $0-2$ points), blinding ( $0-2$ points), and the handling of drop-outs (0-1 point). Each study was scored independently by the authors, who were blind to each other's assessments. The interrater reliability of these scores was good (Cohen's $\kappa=0.67)$. Where a discrepancy existed, this was resolved by a joint evaluation, and the consensus value was entered in Table 2.

\section{Results}

A total of 280 papers were examined, of which 13 fulfilled the criteria for inclusion in this review. A further seven papers were retrospective studies examining the possible protective effect of a given drug against PTSD; these papers were not included in the main review. These papers and their findings are summarized in Table 1. Only one of these papers, examining the effect of hydrocortisone on septic shock survivors, found an unequivocal effect of the study drug on PTSD prevention [24]; others reported negative results [25] or used indirect measures of drug efficacy [2630], limiting the conclusions that could be drawn from them, though four studies did find a significant retrospective association between morphine treatment and reductions in PTSD symptoms [27-30].

The details of the thirteen papers included in this review, and their methodological quality, are summarized in Table 2. There was a wide variation in study quality (range 0-5, mean 2.3). Ten papers were randomized, doubleblind, placebo-controlled drug trials, one was a randomized, placebo-controlled study without description of blinding, and two were open-label studies. Individual drugs examined included propranolol (4 studies), hydrocortisone (4 studies), selective serotonin reuptake inhibitors (SSRIs) (2 studies), benzodiazepines ( 2 studies), polyunsaturated fatty acids (1 study), and gabapentin (1 study). Only one study compared pharmacotherapy with psychological interventions [40].

Two studies included only children and adolescents [33, 39], while the remainder were conducted in adults. Studies were conducted across a wide range of settings. The commonest were emergency medical centres or services handling patients with physical trauma $(n=10)$; other settings included critical care settings (2) and paediatric burns units (1). None of the studies examined victims of disasters or mass casualties.

Treatment was initiated within 48 hours of a traumatic exposure in five studies; in a further two, preventive treatment was initiated immediately in an ICU setting. In the remaining studies, treatment was started several days or weeks after exposure to the traumatic event (range 6.7-29.35 days). Follow-up periods ranged from a minimum of 6 weeks to a maximum of 49 months after treatment.

Details of trials pertaining to specific drugs are summarized as shown in Table 2.

3.1. Propranolol. Four studies [31-34] examined the effect of propranolol (dose range 40-160 mg) in preventing PTSD; three of these were randomized controlled trials, and one was an open study. All these studies involved patients presenting to trauma centres for physical injuries, most commonly motor vehicle accidents. Jadad scores for these trials ranged from 0 to 3 . Three studies were conducted in adults and one was conducted in children. The three adult studies [31, 32,34 ] failed to find a significant effect of propranolol over placebo in reducing short- to medium-term rates of PTSD diagnoses (follow-up duration range, 2-8 months), though one study did find a significant effect of propranolol in reducing symptoms of PTSD [32]. The single study examining 
TABLE 1: Papers excluded from the current review.

\begin{tabular}{|c|c|c|c|c|c|}
\hline Study authors & Study population & Study design & Drug used & Outcome measure & Result \\
\hline $\begin{array}{l}\text { (1) Sharp et al., } \\
2010[25]\end{array}$ & $\begin{array}{l}\text { Children with } \\
\text { severe burns, } \\
n=363\end{array}$ & Chart review & Propranolol & Diagnosis of ASD & $\begin{array}{l}\text { No effect of } \\
\text { propranolol in } \\
\text { preventing ASD after } \\
1 \text { month }\end{array}$ \\
\hline $\begin{array}{l}\text { (2) Schelling et } \\
\text { al., } 1999 \text { [24] }\end{array}$ & $\begin{array}{l}\text { Adults surviving } \\
\text { septic shock, } \\
n=54 \text { ( } 27 \\
\text { receiving the drug, } \\
27 \text { controls) }\end{array}$ & $\begin{array}{l}\text { Retrospective } \\
\text { case-control }\end{array}$ & $\begin{array}{l}\text { Hydrocortisone } \\
100 \mathrm{mg} \text {, followed } \\
\text { by } 0.18 \mathrm{mg} / \mathrm{kg} / \mathrm{hr}\end{array}$ & $\begin{array}{l}\text { Diagnosis of PTSD } \\
\text { as per } \\
\text { Posttraumatic } \\
\text { Stress Syndrome-10 } \\
\text { Inventory }\end{array}$ & $\begin{array}{l}\text { Significantly lower } \\
\text { rates of PTSD in } \\
\text { patients receiving } \\
\text { hydrocortisone }(5 / 27 \\
\text { versus } 16 / 27 \text { controls, } \\
P=.01)\end{array}$ \\
\hline $\begin{array}{l}\text { (3) Kobayashi et } \\
\text { al., } 2011 \text { [26] }\end{array}$ & $\begin{array}{l}\text { Adult victims of } \\
\text { traffic accidents } \\
\text { ( } n=255 ; 23 \\
\text { receiving the drug, } \\
232 \text { controls) }\end{array}$ & $\begin{array}{l}\text { Retrospective } \\
\text { case-control }\end{array}$ & Salbutamol & $\begin{array}{l}\text { PTSD symptoms as } \\
\text { per CAPS }\end{array}$ & $\begin{array}{l}\text { Lower CAPS scores in } \\
\text { the salbutamol group } \\
\text { at } 6 \text { weeks; only the } \\
\text { re-experiencing } \\
\text { sub-score was lower } \\
\text { in this group after } 1 \\
\text { year }\end{array}$ \\
\hline $\begin{array}{l}\text { (4) Saxe et al., } \\
2001 \text { [27] }\end{array}$ & $\begin{array}{l}\text { Hospitalized } \\
\text { children with } \\
\text { burns, aged 6-16 } \\
(n=24)\end{array}$ & $\begin{array}{l}\text { Prospective } \\
\text { observational } \\
\text { study }\end{array}$ & Morphine & $\begin{array}{l}\text { PTSD symptoms as } \\
\text { per Child PTSD } \\
\text { Reaction Index }\end{array}$ & $\begin{array}{l}\text { Significant correlation } \\
\text { between morphine } \\
\text { dose received and } \\
\text { 6-month decrease in } \\
\text { PTSD symptoms }\end{array}$ \\
\hline $\begin{array}{l}\text { (5) Bryant et al., } \\
2009 \text { [28] }\end{array}$ & $\begin{array}{l}\text { Hospitalized } \\
\text { patients with } \\
\text { traumatic injuries } \\
\text { ( } n=155 ; 17 \text { with } \\
\text { PTSD, } 138 \text { without) }\end{array}$ & Chart review & Morphine & $\begin{array}{l}\text { Amount of } \\
\text { morphine used in } \\
\text { patients with and } \\
\text { without PTSD }\end{array}$ & $\begin{array}{l}\text { Patients diagnosed } \\
\text { with PTSD at } 3 \\
\text { months received } \\
\text { significantly less } \\
\text { morphine }\end{array}$ \\
\hline $\begin{array}{l}\text { (6) Stoddard et } \\
\text { al., } 2009 \text { [29] }\end{array}$ & $\begin{array}{l}\text { Hospitalized } \\
\text { children with } \\
\text { burns, aged } 1-4 \\
\text { ( } n=70 \text {; complete } \\
\text { data available only } \\
\text { for } 11 \text { children) } \\
\end{array}$ & $\begin{array}{l}\text { Prospective } \\
\text { observational } \\
\text { study }\end{array}$ & Morphine & $\begin{array}{l}\text { PTSD symptoms as } \\
\text { per CDSC-B Child } \\
\text { Stress Disorders } \\
\text { Checklist-Burns } \\
\text { Version }\end{array}$ & $\begin{array}{l}\text { Significant correlation } \\
\text { between morphine } \\
\text { dose received and } \\
\text { 6-month decrease in } \\
\text { PTSD symptoms }\end{array}$ \\
\hline $\begin{array}{l}\text { (7) Holbrook et } \\
\text { al., } 2010[30]\end{array}$ & $\begin{array}{l}\text { Military personnel } \\
\text { with combat } \\
\text { trauma ( } n=696 ; \\
243 \text { with PTSD, } \\
453 \text { without) }\end{array}$ & Chart review & Morphine & $\begin{array}{l}\text { Rates of morphine } \\
\text { use in patients with } \\
\text { and without PTSD }\end{array}$ & $\begin{array}{l}\text { Lower morphine use } \\
\text { in those with PTSD } \\
(61 \%) \text { than those } \\
\text { without }(76 \% \text {; } \\
P<.001)\end{array}$ \\
\hline
\end{tabular}

CAPS, clinician-assessed PTSD scale; CDSC-B, child stress disorders checklist-burns version.

the efficacy of propranolol in children [33] found no evidence of efficacy overall, but a significantly higher rate of PTSD in girls receiving the drug, suggesting an interaction between gender and drug effects in younger patients.

3.2. Hydrocortisone. Four studies [35-38] assessed the use of hydrocortisone in preventing PTSD. The Jadad scores for these studies ranged from 2 to 3 . Two of these studies were conducted in critically ill patients admitted to intensive care facilities for septic shock [35] and cardiac surgery [36], respectively. These studies used an intravenous loading dose of hydrocortisone followed by a maintenance infusion during the course of hospitalization. One of these studies reported outcomes in terms of PTSD diagnosis and found a positive effect of the drug at long-term follow-up [35]; the other found a significant decrease in PTSD symptoms in those who had received hydrocortisone, compared with a placebo group, after 6 months [36]. The remaining two studies both examined adult patients exposed to a traumatic event; both found significantly lower PTSD scores in the treatment group after 3 months. There was a trend towards lower rates of diagnosed PTSD in the hydrocortisone group in both these studies, but it failed to reach statistical significance.

3.3. Selective Serotonin Reuptake Inhibitors (SSRIs). Two studies examined the preventive effect of SSRIs against PTSD. The Jadad scores of these trials were 2 and $1[39,40]$. The first, conducted in children and adolescents (mean age 12.35 \pm 3.7 years) being treated in a burns unit, examined the effect of 24 weeks of treatment with sertraline (dosed flexibly 


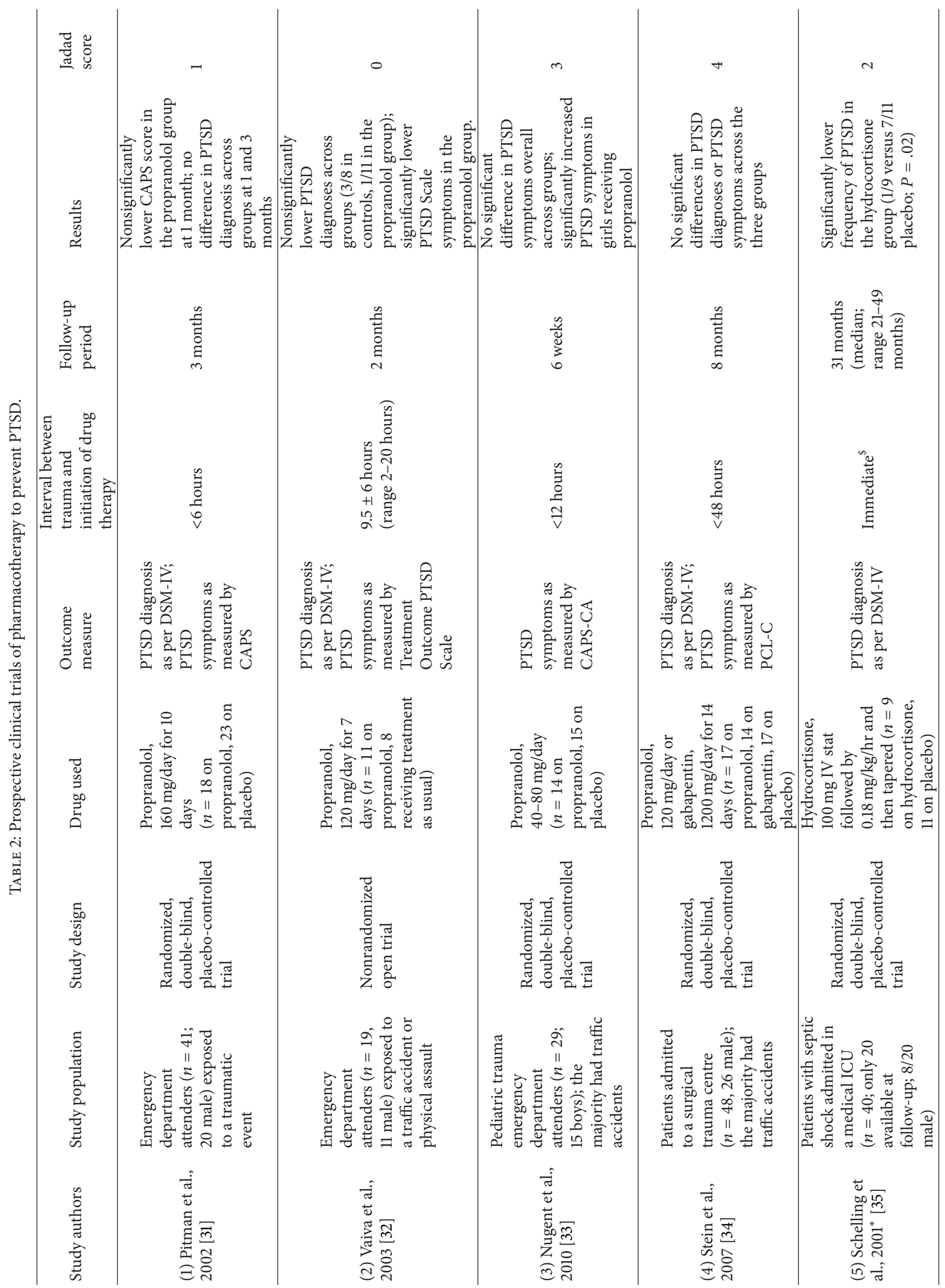




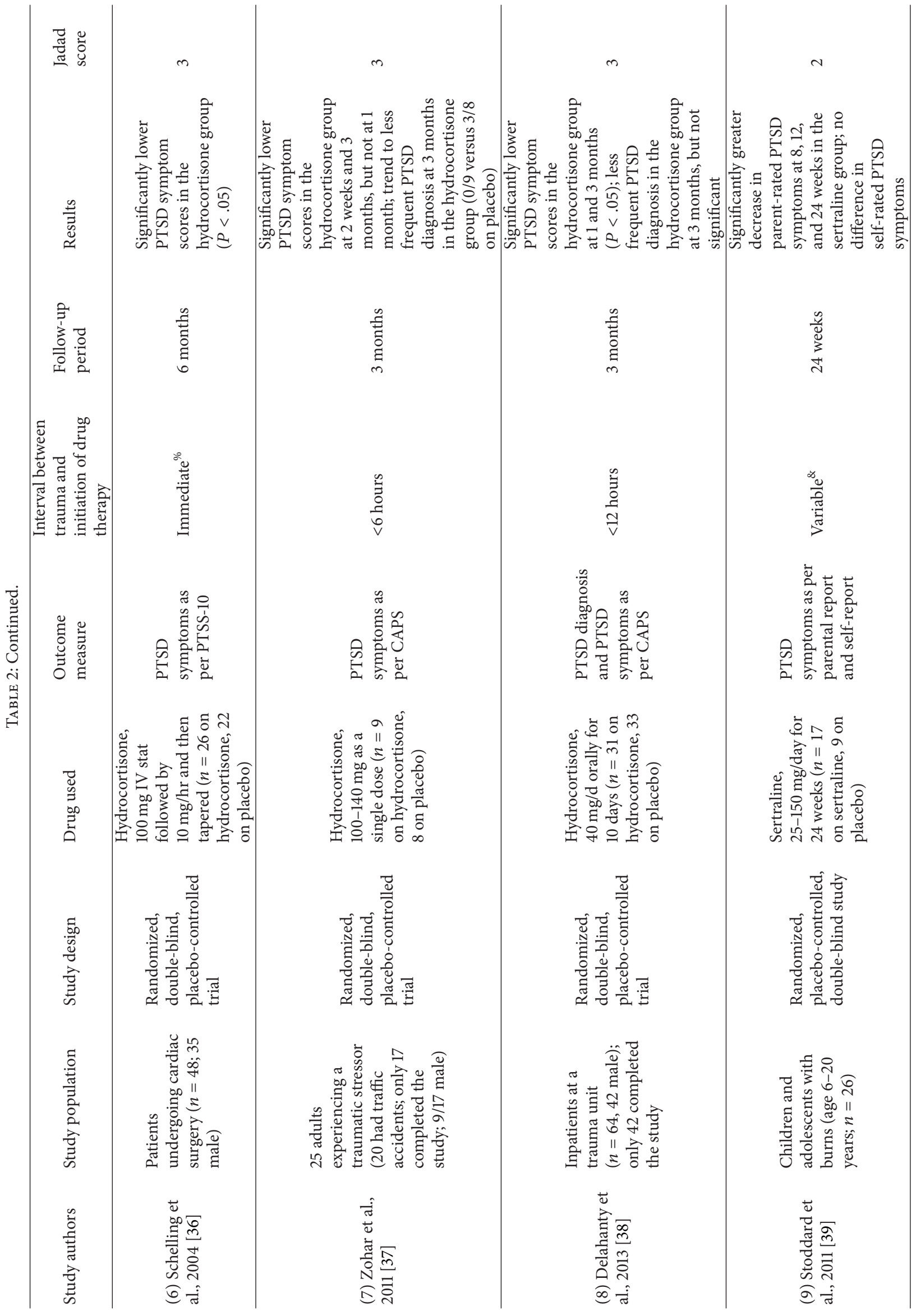




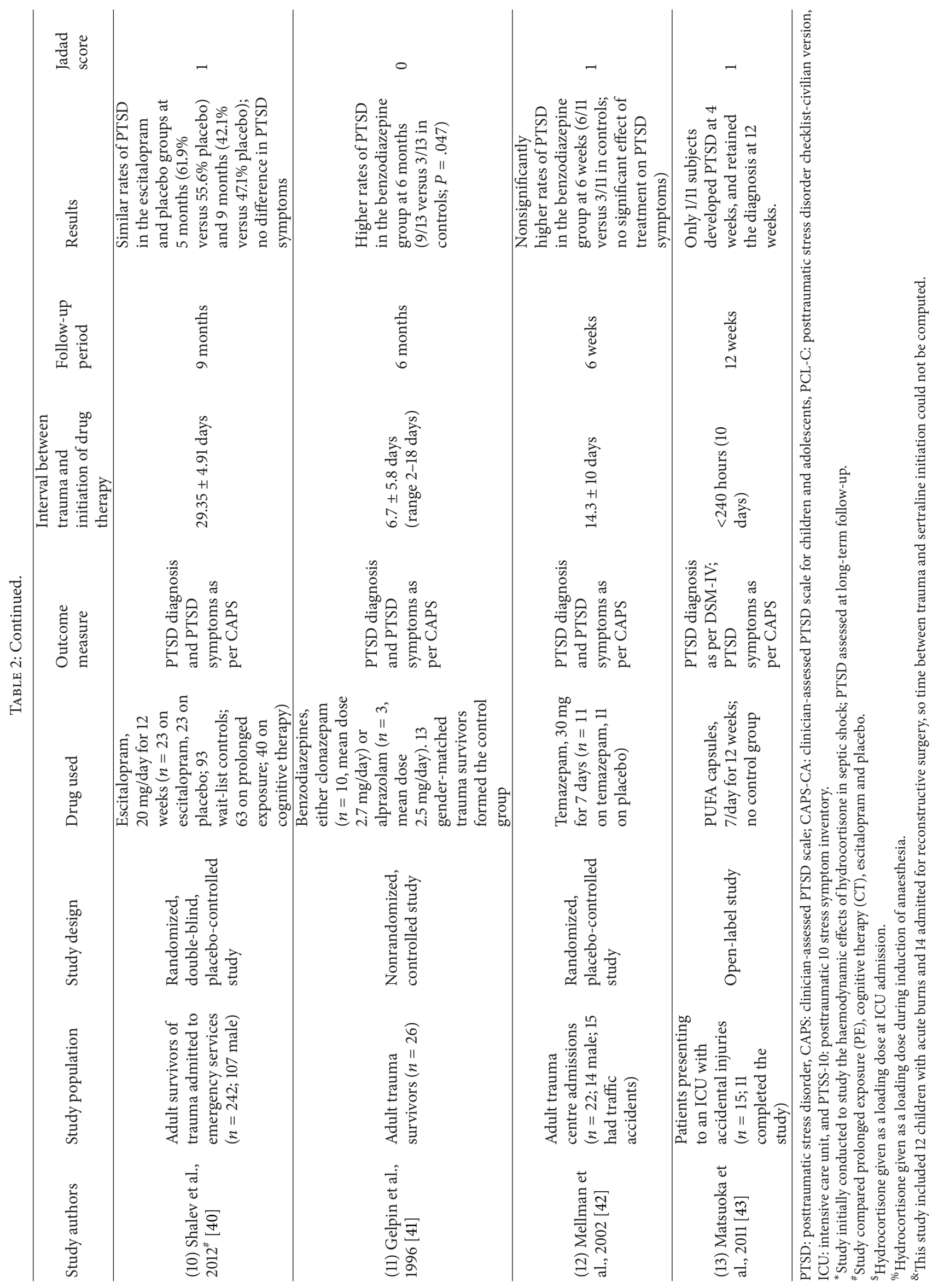


between 25-150 mg/day) on self- and parent-reported PTSD symptoms. This study found a significant effect in favour of sertraline at 8,12 , and 24 weeks for parent-reported symptoms, but not for child-reported symptoms. Of note, this study included 12 children with acute burns and 14 seeking reconstructive surgery; this heterogeneity may have accounted for the equivocal results obtained [39]. A second study was part of a larger, multiarm trial of interventions to prevent PTSD in adult trauma patients. This study found no effect of treatment with escitalopram (dose $20 \mathrm{mg}$ /day) on preventing PTSD when compared with placebo; on the other hand, psychological interventions (prolonged exposure and cognitive therapy) showed significant efficacy in the other arms of this study [40].

3.4. Benzodiazepines. Two small studies, one open-label [41] and one randomized [42], assessed the efficacy of benzodiazepines in adult trauma patients; the Jadad scores of these trials were 0 and 1 , respectively. In both these studies, drug treatment was started several days after trauma exposure in most patients. Both studies found an unfavourable outcome for the study drug, with higher rates of PTSD at follow-up in the treatment groups (pooled rates 15/24 in the benzodiazepine groups, $6 / 24$ in the placebo groups; $P=.01$ ). Of all the treatments examined in this review, benzodiazepines appear to be the only ones which paradoxically increase PTSD rates.

3.5. Gabapentin. A single study of high quality (Jadad score 4) compared the effects of gabapentin, propranolol, and placebo, initiated within 48 hours of exposure, in preventing PTSD in adult patients following a physical injury. At 8 months, there was no significant difference between the three groups in terms of PTSD diagnosis or PTSD symptoms [34].

3.6. Polyunsaturated Fatty Acids (PUFA). A small openlabel study examined the effects of 12 weeks of treatment with fixed dose PUFA capsules, each containing $1470 \mathrm{mg}$ docosahexaenoic acid and $147 \mathrm{mg}$ eicosapentaenoic acid (7 capsules/day) on PTSD outcomes in 15 adult patients exposed to an accidental injury [43]. This study had a Jadad score of 1. 11 patients who completed the study, and only 1 patient developed PTSD; however, due to the lack of a control group, a true preventive effect could not be demonstrated.

\section{Discussion}

Factors affecting study results are as follows.

4.1. Outcome Measures. Of thirteen trials reviewed, twelve provided information that could be used to make inferences regarding efficacy. Nine studies reported outcomes in terms of PTSD diagnoses using the DSM-IV criteria. Of these studies, only one-a trial of hydrocortisone in patients hospitalized for septic shock-reported an unequivocally lower frequency of PTSD in the treatment group [35]. On the other hand, seven papers reported outcomes in terms of PTSD symptoms measured on a standardized, clinical-rated scale; of these, three found consistently lower PTSD symptom scores in the drug group $[32,36,38]$, and a fourth found lower PTSD scores at two out of three assessments [37]. The drugs used in these studies were propranolol [32] or hydrocortisone [36-38]. Three of these four papers also reported outcomes for PTSD diagnoses, and all found lower rates of PTSD in their respective treatment groups, though these differences were not statistically significant. This suggests that even when pharmacotherapy with hydrocortisone or propranolol does not prevent PTSD, it may reduce its severity in some cases; alternately, these studies may have been underpowered to detect differences in the frequency of categorical diagnoses.

4.2. Study Quality. There was significant variation in quality across studies. The mean Jadad score was 1.85 , indicating a generally poor study quality. Using a cut-off Jadad score of 3 , five papers could be categorized as being of good quality [33, 34, 36-38]. Two of these studies reported outcomes in terms of PTSD diagnosis, with a negative result in one case [34] and a nonsignificantly lower rate of PTSD in the other [38]. All five studies reported outcomes in terms of PTSD symptoms on standard rating scales; of these, three studies, all involving hydrocortisone, had a positive outcome [36-38].

In comparison, of eight studies scoring below 3 on the Jadad scale, one of seven measuring this outcome demonstrated a positive effect in terms of PTSD diagnoses [35], and two of four measuring PTSD symptoms had findings in favour of the study drug [32, 39]. This suggests that study design had little effect on the results obtained; furthermore, the best-designed study, with a Jadad score of 4, was negative in terms of drug effects on either PTSD diagnosis or symptom severity [34].

\subsection{Time Interval between Trauma Exposure and Treatment} Initiation. There is evidence from animal research that there may be a "window of opportunity" immediately after a traumatic event [37, 44] during which the use of medications may prevent PTSD and that administering treatment after this period may be ineffective. This period may last only for a few hours [37]. Four studies began drug administration within 6 hours of trauma exposure; of these, a trial of propranolol was negative [31], two trials of hydrocortisone in medical settings were positive $[35,36]$, and a trial of hydrocortisone in adult trauma patients found some evidence of efficacy [37]. In seven other studies in which treatments were administered over 6 hours after trauma exposure, only two reported an effect of the drug in attenuating PTSD symptoms $[32,38]$; in both these studies, the drug was administered within 12 hours of trauma exposure. Studies in which treatment was begun 48 hours or more after trauma exposure were uniformly negative [34, 40-42]. Though the small numbers preclude a meaningful comparison, these findings suggest that even if effective, pharmacotherapy to prevent PTSD may work best when given no more than 12 hours after a traumatic exposure. On the other hand, psychological interventions may be effective even when administered several days after an exposure [40]. 
4.4. Nature of the Study Population. Of the thirteen studies reviewed above, the majority recruited patients who had experienced physical trauma, most commonly in the form of motor vehicle accidents. Two studies were conducted in patients in ICU settings who were at risk for PTSD owing to the grave nature of their illness and/or invasive medical procedures $[35,36]$, and two studies were conducted in children with either physical trauma [33] or burns [39]. It is not possible, with the existing data, to comment on whether the type of trauma or the age of the study population had a significant effect on outcomes; however, there was some evidence of a gender effect in the trial of propranolol in children exposed to physical trauma, with girls in the treatment group showing a paradoxically worse outcome [33].

4.5. Nature of the Drug Used. The two trials of benzodiazepines [41, 42] showed uniformly poor results, with trends towards worse outcomes in the form of higher rates of PTSD in the treatment groups. This unexpected negative effect may arise from the fact that benzodiazepines block the normal cortisol response to trauma, and this response may be important in fear responses [45]; alternately, benzodiazepines may need to be given before rather than after a traumatic event if they are to have a preventive effect [22].

Results with propranolol were largely negative, with only one small study (out of four reviewed) finding a significant difference in PTSD scores [32]. Though this may result from the individual studies being underpowered, research in animals suggests that the ineffectiveness of propranolol may be due to the fact that traumatic stress-related processes are not correlated with the effects of propranolol on either autonomic activity or learning [46].

All four studies of hydrocortisone reported positive results, though only one demonstrated a clear reduction in PTSD diagnosis [35]. Though promising and neurobiologically plausible $[22,45]$, the interpretation of these results is confounded by the fact that two of these studies were conducted in ICU settings, in which hydrocortisone may have corrected an underlying physiological imbalance [35, 36], and effects on PTSD may have been indirect. However, one of the non-ICU studies was probably underpowered [37] and the other suffered from high dropout rates [38]; when the 3-month outcomes of these two studies were combined, a significant difference in favour of hydrocortisone for the diagnosis of PTSD was found (pooled frequencies: $0 / 33$ for 3-month PTSD diagnosis in the hydrocortisone group; $6 / 30$ for placebo; $P=.009$, Fisher's exact test), suggesting that this drug may be effective even outside critical care settings.

Though SSRIs are effective treatments for established PTSD [4], their preventive efficacy cannot be established from the above studies. This may reflect the relatively long period between trauma exposure and initiation of treatment in both studies, as discussed above. Given the apparent efficacy of SSRIs in an animal model of PTSD [47], trials of more immediate treatment with these drugs in the aftermath of trauma may be indicated.

\section{Ethical Issues}

Following initial reports of the use of propranolol to prevent PTSD, concerns were raised about the possible undesirable effects of such a form of treatment to "erase" unpleasant memories, as well as the medicalization of negative life events by the medical profession or drug manufacturers. More fancifully, it has been argued that such treatments may even disrupt a person's sense of self, or lead to a dystopic society [48]. Given the evidence reviewed above about the actual efficacy of propranolol and other drugs in preventing PTSD, such concerns seem premature; moreover, in highrisk groups, such as military veterans experiencing combat trauma, withholding an effective preventive treatment-if one existed-could itself be unethical [49]. If and when such treatments are approved and available on a large scale, they will need to be handled carefully, and informed consent should be obtained in all cases [48].

\section{Applicability of the Existing Research to Clinical Practice}

As of now, it is premature to recommend any of the treatment approaches reviewed above-including hydrocortisone-in routine clinical practice. Further research, involving larger numbers of patients exposed to different sorts of trauma in various settings, needs to be conducted before this can be done. There is little evidence for the use of other drugs, and benzodiazepines in particular should be avoided as they may actually worsen patient outcomes. In patients presenting days or weeks after a traumatic exposure, psychological interventions may be more beneficial [40]. Similar caveats apply to the use of these drugs in disaster or mass casualty settings, where they have never been tested.

\section{Future Directions}

A variety of other pharmacological agents have shown promise in animal models of PTSD; these include corticotropin-releasing factor (CRF) antagonists [50], cannabinoids [51], inhibitors of protein synthesis [52], and inhibitors of steroid synthesis, such as ketoconazole [53]. The safety, efficacy, and feasibility of these approaches in humans have yet to be established. In the meantime, largescale clinical trials of hydrocortisone and of SSRIs during the "window period" may clarify the role of these drugs in clinical practice, as well as their efficacy compared to psychological interventions. Systematic trials of morphine, which has shown promise in observational studies [27-30], are also required.

\section{Conclusion}

The field of pharmacotherapy for the prevention of PTSD is still in its infancy. The early enthusiasm for propranolol therapy has not been justified by the results of controlled trials. The existing literature suggests that hydrocortisone therapy is promising, both in and outside intensive care 
settings, and this approach should be tested on a larger scale. However, no specific drug therapy can be routinely recommended yet for the prevention of PTSD in clinical or disaster settings.

\section{Conflict of Interests}

The authors declare that there is no conflict of interests regarding the publication of this paper.

\section{References}

[1] R. Yehuda, "Post-traumatic stress disorder," The New England Journal of Medicine, vol. 346, no. 2, pp. 108-114, 2002.

[2] Y. Neria, A. Nandi, and S. Galea, "Post-traumatic stress disorder following disasters: a systematic review," Psychological Medicine, vol. 38, no. 4, pp. 467-480, 2008.

[3] J. C. Jackson, R. P. Hart, S. M. Gordon, R. O. Hopkins, T. D. Girard, and E. W. Ely, "Post-traumatic stress disorder and posttraumatic stress symptoms following critical illness in medical intensive care unit patients: assessing the magnitude of the problem," Critical Care, vol. 11, no. 1, p. R27, 2007.

[4] B. D. Grinage, "Diagnosis and management of post-traumatic stress disorder," American Family Physician, vol. 68, no. 12, pp. 2401-2409, 2003.

[5] F. Lamprecht and M. Sack, "Posttraumatic stress disorder revisited," Psychosomatic Medicine, vol. 64, no. 2, pp. 222-237, 2002.

[6] A. Perkonigg, H. Pfister, M. B. Stein et al., "Longitudinal course of posttraumatic stress disorder and posttraumatic stress disorder symptoms in a community sample of adolescents and young adults," The American Journal of Psychiatry, vol. 162, no. 7, pp. 1320-1327, 2005.

[7] I. R. Galatzer-Levy, Y. Ankri, S. Freedman et al., "Early PTSD symptom trajectories: persistence, recovery, and response to treatment: results from the Jerusalem trauma outreach and prevention study (J-TOPS)," PLOS ONE, vol. 8, Article ID e70084, 2013.

[8] D. Koren, I. Arnon, and E. Klein, "Long term course of chronic posttraumatic stress disorder in traffic accident victims: a three-year prospective follow-up study," Behaviour Research and Therapy, vol. 39, no. 12, pp. 1449-1458, 2001.

[9] Z. Solomon and M. Mikulincer, "Trajectories of PTSD: a 20-year longitudinal study," American Journal of Psychiatry, vol. 163, no. 4, pp. 659-666, 2006.

[10] N. Breslau, "Outcomes of posttraumatic stress disorder," Journal of Clinical Psychiatry, vol. 62, supplement 17, pp. 55-59, 2001.

[11] C. S. North, J. Oliver, and A. Pandya, "Examining a comprehensive model of disaster-related posttraumatic stress disorder in systematically studied survivors of 10 disasters," The American Journal of Public Health, vol. 102, no. 10, pp. e40-e48, 2012.

[12] S. P. Cahill and K. Pontoski, "Post-traumatic stress disorder and acute stress disorder I: their nature and assessment considerations," Psychiatry, vol. 2, no. 4, pp. 14-25, 2005.

[13] R. A. Bryant, "Acute stress disorder as a predictor of posttraumatic stress disorder: a systematic review," Journal of Clinical Psychiatry, vol. 72, no. 2, pp. 233-239, 2011.

[14] R. A. Bryant, M. Creamer, M. O’Donnell, D. Silove, and A. C. McFarlane, "The capacity of acute stress disorder to predict posttraumatic psychiatric disorders," Journal of Psychiatric Research, vol. 46, no. 2, pp. 168-173, 2012.
[15] M. Hansen and A. Elklit, "Does acute stress disorder predict posttraumatic stress disorder following bank robbery?" Journal of Interpersonal Violence, vol. 28, no. 1, pp. 25-44, 2013.

[16] M. Shevlin, P. Hyland, and A. Elklit, "Different profiles of acute stress disorder differentially predict posttraumatic stress disorder in a large sample of female victims of sexual trauma," Psychological Assessment. In press.

[17] K. Ponniah and S. D. Hollon, "Empirically supported psychological treatments for adult acute stress disorder and posttraumatic stress disorder: a review," Depression and Anxiety, vol. 26, no. 12, pp. 1086-1109, 2009.

[18] S. E. Hobfoll, P. Watson, C. C. Bell et al., "Five essential elements of immediate and mid-term mass trauma intervention: empirical evidence," Psychiatry, vol. 70, no. 4, pp. 283-315, 2007.

[19] S. C. Rose, J. Bisson, R. Churchill, and S. Wessely, "Psychological debriefing for preventing post traumatic stress disorder," Cochrane Database of Systematic Reviews, no. 2, Article ID CD000650, 2002.

[20] C. A. Forneris, G. Gartlehner, K. A. Brownley et al., "Interventions to prevent post-traumatic stress disorder: a systematic review," American Journal of Preventive Medicine, vol. 44, no. 6, pp. 635-650, 2013.

[21] M. van Ommeren, S. Saxena, and B. Saraceno, "Aid after disasters," British Medical Journal, vol. 330, no. 7501, pp. 11601161, 2005.

[22] R. K. Pitman and D. L. Delahanty, "Conceptually driven pharmacologic approaches to acute trauma," CNS Spectrums, vol. 10, no. 2, pp. 99-106, 2005.

[23] A. R. Jadad, R. A. Moore, D. Carroll et al., "Assessing the quality of reports of randomized clinical trials: is blinding necessary?" Controlled Clinical Trials, vol. 17, no. 1, pp. 1-12, 1996.

[24] G. Schelling, C. Stoll, H.-P. Kapfhammer et al., "The effect of stress doses of hydrocortisone during septic shock on posttraumatic stress disorder and health-related quality of life in survivors," Critical Care Medicine, vol. 27, no. 12, pp. 2678 $2683,1999$.

[25] S. Sharp, C. Thomas, L. Rosenberg, M. Rosenberg, and W. Meyer III, "Propranolol does not reduce risk for acute stress disorder in pediatric burn trauma," The Journal of trauma, vol. 68, no. 1, pp. 193-197, 2010.

[26] I. Kobayashi, E. Sledjeski, W. Fallon, E. Spoonster, D. Riccio, and D. Delahanty, "Effects of early albuterol (salbutamol) administration on the development of posttraumatic stress symptoms," Psychiatry Research, vol. 185, no. 1-2, pp. 296-298, 2011.

[27] G. Saxe, F. Stoddard, D. Courtney et al., "Relationship between acute morphine and the course of PTSD in children with burns," Journal of the American Academy of Child and Adolescent Psychiatry, vol. 40, no. 8, pp. 915-921, 2001.

[28] R. A. Bryant, M. Creamer, M. O'Donnell, D. Silove, and A. C. McFarlane, "A study of the protective function of acute morphine administration on subsequent posttraumatic stress disorder," Biological Psychiatry, vol. 65, no. 5, pp. 438-440, 2009.

[29] F. J. Stoddard, E. A. Sorrentino, T. A. Ceranoglu et al., "Preliminary evidence for the effects of morphine on posttraumatic stress disorder symptoms in one- to four-year-olds with burns," Journal of Burn Care and Research, vol. 30, no. 5, pp. 836-843, 2009.

[30] T. L. Holbrook, M. R. Galarneau, J. L. Dye, K. Quinn, and A. L. Dougherty, "Morphine use after combat injury in Iraq and posttraumatic stress disorder," The New England Journal of Medicine, vol. 362, no. 2, pp. 110-117, 2010. 
[31] R. K. Pitman, K. M. Sanders, R. M. Zusman et al., "Pilot study of secondary prevention of posttraumatic stress disorder with propranolol," Biological Psychiatry, vol. 51, no. 2, pp. 189-192, 2002.

[32] G. Vaiva, F. Ducrocq, K. Jezequel et al., "Immediate treatment with propranolol decreases posttraumatic stress disorder two months after trauma," Biological Psychiatry, vol. 54, no. 9, pp. 947-949, 2003.

[33] N. R. Nugent, N. C. Christopher, J. P. Crow, L. Browne, S. Ostrowski, and D. L. Delahanty, "The efficacy of early propranolol administration at reducing PTSD symptoms in pediatric injury patients: a pilot study," Journal of Traumatic Stress, vol. 23, no. 2, pp. 282-287, 2010.

[34] M. B. Stein, C. Kerridge, J. E. Dimsdale, and D. B. Hoyt, "Pharmacotherapy to prevent PTSD: Results from a randomized controlled proof-of-concept trial in physically injured patients," Journal of Traumatic Stress, vol. 20, no. 6, pp. 923-932, 2007.

[35] G. Schelling, J. Briegel, B. Roozendaal, C. Stoll, H.-B. Rothenhäusler, and H.-P. Kapfhammer, "The effect of stress doses of hydrocortisone during septic shock on posttraumatic stress disorder in survivors," Biological Psychiatry, vol. 50, no. 12, pp. 978-985, 2001.

[36] G. Schelling, E. Kilger, B. Roozendaal et al., "Stress doses of hydrocortisone, traumatic memories, and symptoms of posttraumatic stress disorder in patients after cardiac surgery: a randomized study," Biological Psychiatry, vol. 55, no. 6, pp. 627$633,2004$.

[37] J. Zohar, H. Yahalom, N. Kozlovsky et al., "High dose hydrocortisone immediately after trauma may alter the trajectory of PTSD: interplay between clinical and animal studies," European Neuropsychopharmacology, vol. 21, no. 11, pp. 796-809, 2011.

[38] D. L. Delahanty, C. Gabert-Quillen, S. A. Ostrowski et al., "The efficacy of initial hydrocortisone administration at preventing posttraumatic distress in adult trauma patients: a randomized trial," CNS Spectrums, vol. 18, no. 2, pp. 103-111, 2013.

[39] F. J. Stoddard Jr., R. Luthra, E. A. Sorrentino et al., "A randomized controlled trial of sertraline to prevent posttraumatic stress disorder in burned children," Journal of Child and Adolescent Psychopharmacology, vol. 21, no. 5, pp. 469-477, 2011.

[40] A. Y. Shalev, Y. Ankri, Y. Israeli-Shalev, T. Peleg, R. Adessky, and S. Freedman, "Prevention of posttraumatic stress disorder by early treatment: results from the Jerusalem trauma outreach and prevention study," Archives of General Psychiatry, vol. 69, no. 2, pp. 166-176, 2012.

[41] E. Gelpin, O. Bonne, T. Peri, D. Brandes, and A. Y. Shalev, "Treatment of recent trauma survivors with benzodiazepines: a prospective study," Journal of Clinical Psychiatry, vol. 57, no. 9, pp. 390-394, 1996.

[42] T. A. Mellman, V. Bustamante, D. David, and A. I. Fins, "Hypnotic medication in the aftermath of trauma," Journal of Clinical Psychiatry, vol. 63, no. 12, pp. 1183-1184, 2002.

[43] Y. Matsuoka, D. Nishi, N. Yonemoto, K. Hamazaki, T. Hamazaki, and K. Hashimoto, "Potential role of brain-derived neurotrophic factor in omega-3 fatty acid supplementation to prevent posttraumatic distress after accidental injury: an openlabel pilot study," Psychotherapy and Psychosomatics, vol. 80, no. 5, pp. 310-312, 2011.

[44] H. Cohen, M. A. Matar, D. Buskila, Z. Kaplan, and J. Zohar, "Early post-stressor intervention with high-dose corticosterone attenuates posttraumatic stress response in an animal model of posttraumatic stress disorder," Biological Psychiatry, vol. 64, no. 8, pp. 708-717, 2008.
[45] J. Zohar, R. Sonnino, A. Juven-Wetzler, and H. Cohen, "Can posttraumatic stress disorder be prevented?" CNS spectrums, vol. 14, supplement 1, pp. 44-51, 2009.

[46] H. Cohen, Z. Kaplan, O. Koresh, M. A. Matar, A. B. Geva, and J. Zohar, "Early post-stressor intervention with propranolol is ineffective in preventing posttraumatic stress responses in an animal model for PTSD," European Neuropsychopharmacology, vol. 21, no. 3, pp. 230-240, 2011.

[47] M. A. Matar, H. Cohen, Z. Kaplan, and J. Zohar, "The effect of early poststressor intervention with sertraline on behavioral responses in an animal model of post-traumatic stress disorder," Neuropsychopharmacology, vol. 31, no. 12, pp. 2610-2618, 2006.

[48] M. Henry, J. R. Fishman, and S. J. Youngner, "Propranolol and the prevention of post-traumatic stress disorder: is it wrong to erase the "sting" of bad memories?" The American Journal of Bioethics, vol. 7, no. 9, pp. 12-20, 2007.

[49] E. Donovan, "Propranolol use in the prevention and treatment of posttraumatic stress disorder in military veterans: forgetting therapy revisited," Perspectives in Biology and Medicine, vol. 53, no. 1, pp. 61-74, 2010.

[50] R. Adamec, D. Fougere, and V. Risbrough, “CRF receptor blockade prevents initiation and consolidation of stress effects on affect in the predator stress model of PTSD," International Journal of Neuropsychopharmacology, vol. 13, no. 6, pp. 747-757, 2010.

[51] E. Ganon-Elazar and I. Akirav, "Cannabinoids prevent the development of behavioral and endocrine alterations in a rat model of intense stress," Neuropsychopharmacology, vol. 37, no. 2, pp. 456-466, 2012.

[52] H. Cohen, Z. Kaplan, M. A. Matar, U. Loewenthal, N. Kozlovsky, and J. Zohar, "Anisomycin, a protein synthesis inhibitor, disrupts traumatic memory consolidation and attenuates posttraumatic stress response in rats," Biological Psychiatry, vol. 60, no. 7, pp. 767-776, 2006.

[53] H. Cohen, J. Benjamin, Z. Kaplan, and M. Kotler, "Administration of high-dose ketoconazole, an inhibitor of steroid synthesis, prevents posttraumatic anxiety in an animal model," European Neuropsychopharmacology, vol. 10, no. 6, pp. 429-435, 2000. 


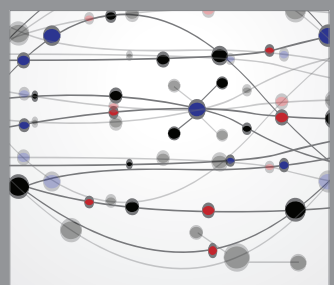

The Scientific World Journal
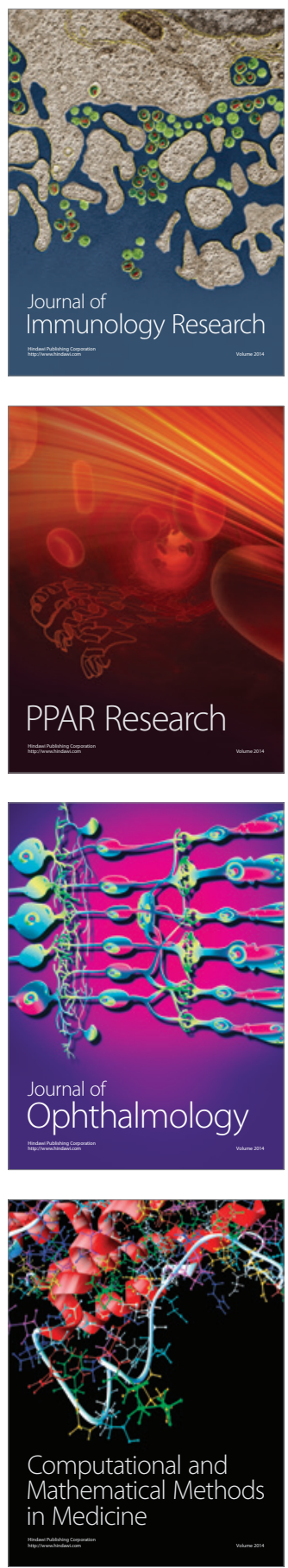

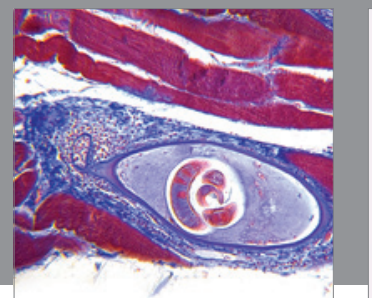

Gastroenterology

Research and Practice
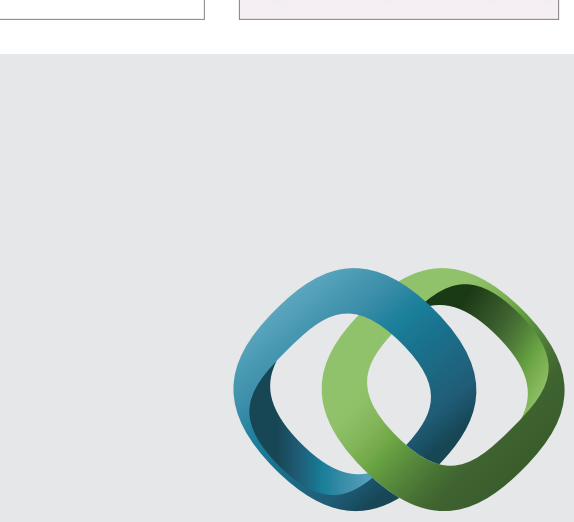

\section{Hindawi}

Submit your manuscripts at

http://www.hindawi.com
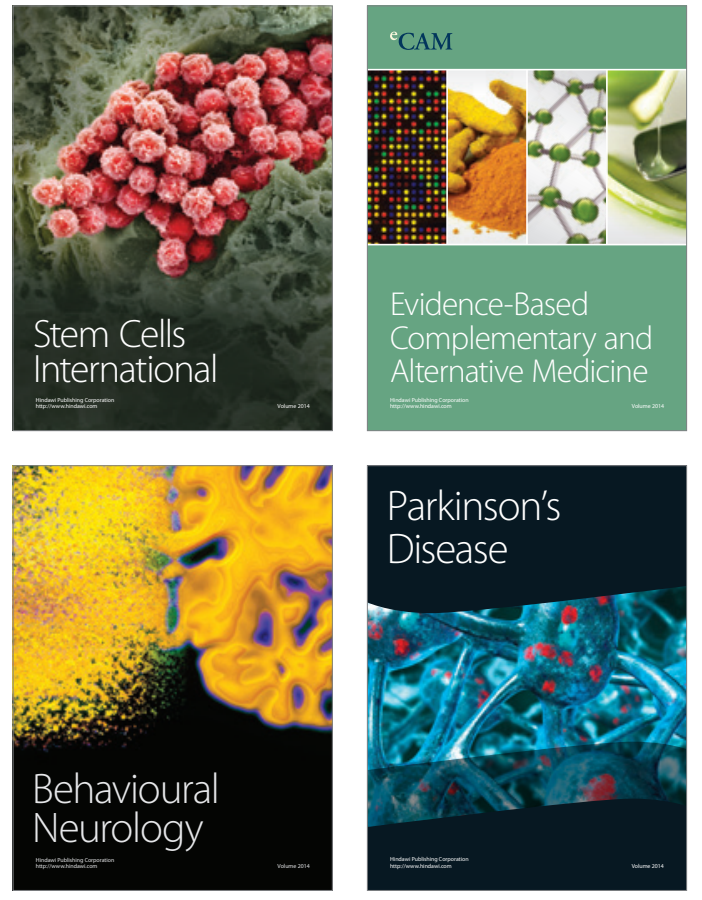
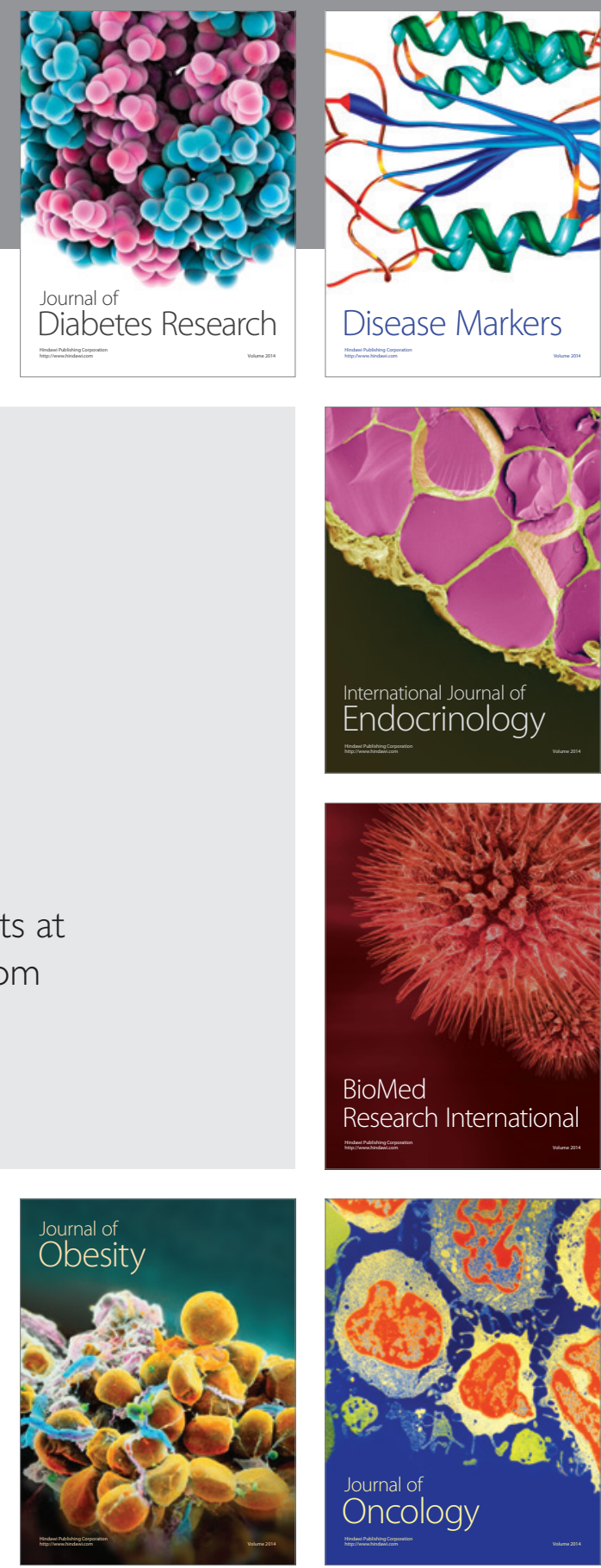

Disease Markers
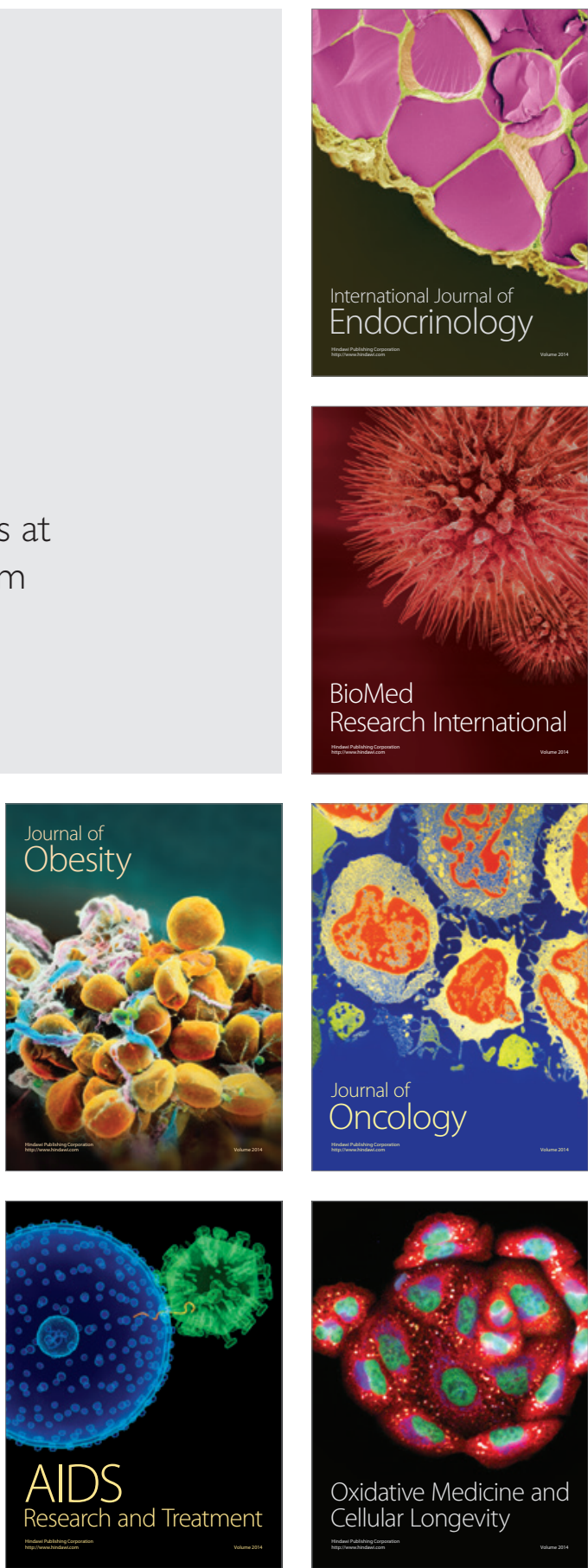